\title{
How Reliable Are Reports of Early Adolescent Reproductive and Sexual Health Events In Demographic and Health Surveys?
}

\section{By Sarah E. Neal and Victoria Hosegood}

Sarah E. Neal is British Academy Postdoctoral Research Fellow, and Victoria Hosegood is professor of demography and family health, both in the Department of Social Statistics and Demography, University of Southampton, UK.

\begin{abstract}
CONTEXT: Age at sexual debut, age at first marriage or first union and age at first birth are among the most widely used indicators of health and well-being for female adolescents. However, the accuracy of estimates for these indicators, particularly for younger adolescents, is poorly understood.
\end{abstract}

METHODS: For each of nine countries in Africa and Latin America, Demographic and Health Survey (DHS) data from two surveys conducted five years apart were used to examine women's reports of age at sexual debut, marriage or first union, and first birth. The consistency of estimates between surveys and across birth cohorts is described, focusing particularly on the reporting of events occurring before age 15 and age 16.

RESULTS: Marked differences in estimates for very early first births and marriage were found. Women aged 15-19 were much less likely to report marriages and first births before age 15 than were women from the same birth cohort when asked five years later at ages 20-24. Early sexual debut was reported more consistently in consecutive surveys than early marriages or births.

CONCLUSIONS: Caution should be exercised when inferring changes in early adolescent sexual and reproductive health on the basis of estimates from the DHS. Greater effort should be made to develop data collection instruments that reduce misreporting of self-reported data from women sampled in household surveys.

International Perspectives on Sexual and Reproductive Health, 2015, 41(4):210-217, doi: 10.1363/4121015
The health and well-being of female adolescents is considered crucial to the continued development of low-income countries. ${ }^{1}$ Among the most widely used indicators of health and well-being for female adolescents are age at sexual debut (also described as age at first sex), age at first marriage or first union and age at first birth. Demographic and Health Survey (DHS) data are widely used to estimate these indicators, and DHS country reports routinely present the percentage of women aged 15-49 who experience sexual debut, marry or give birth before age 15 , grouped into five-year cohorts, and the percentage of women aged 15-19 at time of survey who have started childbearing, by individual year of age. Despite evidence suggesting that social desirability bias and recall bias may exert a strong influence on reports of childbearing, sexual debut and marriage by adolescents, ${ }^{2-4}$ the accuracy of DHS-based estimates of these widely reported indicators is poorly understood. Even less is known about the reliability of data when these events occur in very early adolescence.

There is widespread recognition of the vulnerability of and risks faced by sexually active young adolescents (both in or outside of marriage), ${ }^{5}$ and growing understanding of the need for appropriate sexual health education and services for this age-group. ${ }^{6}$ To support improvements in education and services, age-disaggregated indicators are required to identify need and monitor progress. However, inaccurate data may lead to erroneous interpretations of both the proportions of adolescents experiencing sexual health events and of trends over time. In particular, underestimations of the proportions affected or overestimation of positive trends could lead to complacency about the scale of the problem or false optimism over progress.

In this article, we first examine the consistency of DHS data from two consecutive surveys in each of nine countries on adolescent age at sexual debut, marriage or first union, and first birth across cohorts, disaggregated by age in years. We then carry out further analysis to determine which age-group of respondents (ages 15-19 vs. 20-24) is most likely to provide the most accurate estimates. In the discussion, we consider possible underlying causes for the inconsistencies we have identified and the implications the inconsistencies have for policymakers and researchers who use these data.

\section{Sources of Errors}

The DHS relies on retrospective reporting of events and asks all responding women of reproductive age to report on the same events, e.g., age at sexual debut, age at first marriage or union, and age at first birth. Errors in reporting on reproductive and sexual health events can be divided into three categories: recall error, survey completion issues and social desirability bias. While some of these sources of error are universal, others may be more prevalent in particular age-groups. Recall bias, an unintentional error in which an event is omitted or mistimed, is more common among older women than among younger women because 
more time has elapsed between the survey and the event of interest. ${ }^{7}$ Perceptions of an event such as first marriage or union may be another source of unintentional error because the cultural, social and legal conditions defining such an event may vary. ${ }^{8,9}$ Marriage and union formation may be fluid and, in many countries, are processes rather than single events, often spread out over many years. ${ }^{10-13}$ Responses to questions on the occurrence and timing of marriage or union formation will reflect the current perceptions of respondents when thinking back over the course of their lives, and these perceptions may change as women get older.

Survey completion issues may be a source of intentional bias. In the DHS, the backdating of births is a common problem because respondents who have given birth within five years of the survey are required to complete an additional questionnaire for the child. ${ }^{14}$ Consequently, there is an incentive for the interviewer (and, possibly, for the respondent) to avoid additional work by misreporting births as occurring outside the five-year window. ${ }^{7}$ The age of the respondent may influence the extent to which backdating occurs; interviewers may be less likely to encourage backdating for very young mothers than for older mothers because it could render maternal age at birth implausible.

Studies indicate widespread inconsistencies in data and misreporting of adolescent sexual behavior within surveys and studies. ${ }^{2-4}$ The reporting of the initiation of sexual activity and of the timing of early marriage and childbirth during adolescence may be particularly prone to social desirability bias. Beguy et al.'s study in Nairobi ${ }^{15}$ found that approximately half of adolescents misreported or inconsistently reported sexual experience. The authors argue that while pressure may be felt by young men to overreport sexual experience during adolescence, the opposite is more likely for female respondents, given negative attitudes toward women having sex at a young age or outside of marriage.

Because the legal age of marriage in many countries is older than the traditional norm, ${ }^{16}$ fear of repercussions may lead to overstatement of age at marriage. ${ }^{17}$ In Bangladesh, however, women have been shown to intentionally lower their age at marriage, possibly because of the social desirability of early marriage for women there. ${ }^{18}$

In communities in which sex or childbirth outside of marriage is censured, some women may feel the need to adjust their responses to make it appear that first sex or first birth occurred after marriage. Women may overstate their age at first sex or first birth, backdate their first marriage, or not mention births that happened when they were very young or unmarried. The misrepresentation of the timing and sequence of life events may be an immediate response to being asked sensitive questions or, in some cases, may already be part of the narrative the respondent gives about her life events.

*Because surveys that were conducted over two calendar years were also included, the length of time between a country's surveys ranges from 4.5 to 5.5 years.

\section{METHODS}

Our study uses DHS data from six countries in SubSaharan Africa (Benin, Ghana, Madagascar, Mali, Senegal and Uganda) and three in Latin America (Bolivia, Colombia and the Dominican Republic). These countries were selected because they had two surveys conducted five years apart, ${ }^{*}$ and at least 4\% of women aged 20-24 in the first survey reported a first birth before age 16 .

First, we examine the consistency of reports of sexual debut, marriage and first birth before ages 15, 16 and 19 between the consecutive surveys for each country. The DHS does not observe the same individuals in each survey; however, making comparisons across surveys allows us to examine the consistency of estimates of reproductive health events from women in the same birth cohort obtained at different times. This approach has previously been used

\begin{tabular}{|c|c|c|c|c|}
\hline $\begin{array}{l}\text { Country and age } \\
\text { at first birth }\end{array}$ & Age 15-19 & Age 20-24 & $\begin{array}{l}\text { Percentage } \\
\text { difference }\end{array}$ & $\begin{array}{l}\text { Percentage- } \\
\text { point } \\
\text { difference }\end{array}$ \\
\hline Benin & 2001 & 2006 & & \\
\hline$<15$ & $2.1(1.3-2.9)$ & $4.8(4.1-5.6)$ & 128.6 & 2.7 \\
\hline$<16$ & $4.4(3.1-5.6)$ & $8.8(7.8-9.8)$ & 100.0 & 4.4 \\
\hline$<19$ & $27.9(21.8-34.1)$ & $34.0(32.3-35.6)$ & 21.9 & 6.1 \\
\hline Ghana & 2003 & 2008 & & \\
\hline$<15$ & $0.6(0.2-1.1)$ & $2.2(1.2-3.2)$ & 266.7 & 1.6 \\
\hline$<16$ & $2.0(1.1-2.9)$ & $5.2(3.7-6.7)$ & 160.0 & 3.2 \\
\hline$<19$ & $17.9(12.4-23.5)$ & $23.7(20.9-26.5)$ & 32.4 & 5.8 \\
\hline Madagascar & 2003 & 2008-2009 & & \\
\hline$<15$ & $5.3(4.2-6.4)$ & $7.9(6.9-8.9)$ & 49.1 & 2.6 \\
\hline$<16$ & $9.8(8.1-11.4)$ & $13.9(12.6-15.2)$ & 41.8 & 4.1 \\
\hline$<19$ & $40.7(35.0-46.4)$ & $45.5(43.7-45.0)$ & 11.8 & 4.8 \\
\hline Mali & 2001 & 2006 & & \\
\hline$<15$ & $5.3(4.4-6.1)$ & $9.9(8.7-11.0)$ & 86.8 & 4.6 \\
\hline$<16$ & $12.1(10.6-13.5)$ & $19.8(18.3-21.3)$ & 63.6 & 7.7 \\
\hline$<19$ & $53.4(48.3-58.6)$ & $58.3(56.4-60.1)$ & 9.2 & 4.9 \\
\hline Senegal & 2005 & 2010-2011 & & \\
\hline$<15$ & $2.0(1.6-2.5)$ & $5.8(4.9-6.5)$ & 190.0 & 3.8 \\
\hline$<16$ & $5.7(4.8-6.5)$ & $9.3(8.3-10.3)$ & 63.2 & 3.6 \\
\hline$<19$ & $30.6(26.7-34.5)$ & $28.5(27.0-30.0)$ & -6.9 & -2.1 \\
\hline Uganda & 2006 & 2011 & & \\
\hline$<15$ & $1.4(0.9-1.9)$ & $6.6(5.4-7.8)$ & 371.4 & 5.2 \\
\hline$<16$ & $4.6(3.5-5.7)$ & $12.3(10.7-13.9)$ & 167.4 & 7.7 \\
\hline$<19$ & $45.5(44.4-46.5)$ & 46.1 (43.7-48.6) & 1.3 & 0.6 \\
\hline Bolivia & 2003 & 2008 & & \\
\hline$<15$ & $1.1(0.7-1.4)$ & $1.8(1.3-2.3)$ & 63.6 & 0.7 \\
\hline$<16$ & $3.8(3.1-4.4)$ & $5.2(4.3-6.0)$ & 36.8 & 1.4 \\
\hline$<19$ & $24.2(20.9-27.6)$ & $29.0(27.2-30.6)$ & 19.8 & 4.8 \\
\hline Colombia & 2005 & 2010 & & \\
\hline$<15$ & $1.7(1.4-2.1)$ & $2.3(2.0-2.6)$ & 35.3 & 0.6 \\
\hline$<16$ & $5.5(4.9-6.0)$ & $5.7(5.2-6.2)$ & 3.6 & 0.2 \\
\hline$<19$ & $29.6(27.1-32.0)$ & $28.6(27.6-29.6)$ & -3.4 & -1.0 \\
\hline Dominican Republic & 2005 & 2010 & & \\
\hline$<15$ & $2.6(2.1-3.0)$ & $3.0(2.5-3.5)$ & 15.4 & 0.4 \\
\hline$<16$ & $7.4(6.6-8.3)$ & $8.5(7.7-9.3)$ & 14.9 & 1.1 \\
\hline$<19$ & $33.2(30.1-36.2)$ & $33.8(32.3-35.2)$ & 1.8 & 0.6 \\
\hline
\end{tabular}

Note: Estimates are based on the proportion of the sample exposed to the relevant time period. 


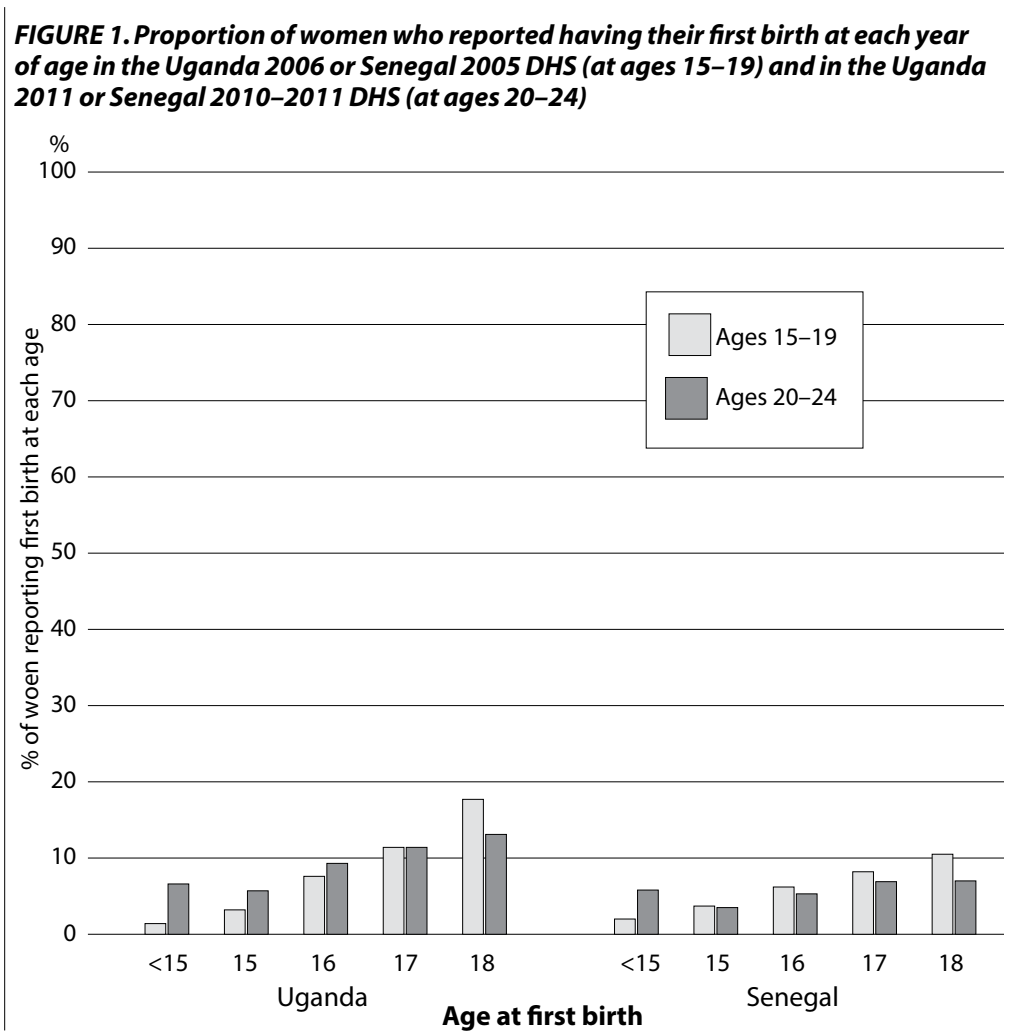

with DHS data to examine estimates of child mortality and age at first sex. ${ }^{19-21}$ When considering the cohort of women aged 15-19 in each survey, only those exposed to the full period of interest are included. Thus, indicators for women younger than 15 are based on all women aged 1519 at time of interview, whereas for indicators for women younger than 16 , only those aged 16-19 at time of interval are included. The percentage difference between the two estimates and the absolute percentage-point difference between estimates are used as measures of consistency.

Second, to get a clearer picture of patterns over time by cohort, we used data from the first DHS in each country to calculate the percentage of women in five-year age-groups through 45-49* reporting that sexual debut, marriage or first birth occurred before age 16. For a subset of surveys in which the differences between surveys are marked, we also present findings of more detailed analyses, drawing on DHS data from three consecutive surveys conducted five years apart, highlighting specific inconsistencies and their possible causes.

\section{RESULTS}

We first estimate the proportion of women reporting each of the three outcomes of interest before ages 15, 16 and 19 (ages 15-19 in the first survey and 20-24 in the second). In the six Sub-Saharan African countries, the proportions of 20-24-year-old women in the second survey who report having had their first birth before age 15 or before age 16

*The youngest age-group (16-19 years) is a four-year, not a five-year, cohort. are markedly higher than those among women in the 1519 or 16-19 age-groups in the survey conducted five years earlier (Table 1, page 211). In Benin, Ghana and Uganda, the proportion in the second survey is at least twice that in the first survey. However, except in Benin and Ghana, the differences between surveys in estimates of births occurring before age 19 are much smaller in terms of percentage change than those for births occurring before ages 15 and 16 , and in several countries, such as Senegal and Mali, the percentage differences and percentage-point differences are very small. Of the three countries in Latin America, Colombia and the Dominican Republic show no differences between the two cohorts, and the only marked difference (more than 50\%) in Bolivia is for births before age 15. Confidence intervals are quite modest and cannot explain the differences in any country in Sub-Saharan Africa for first births before age 15 and age 16 . However, confidence intervals overlap for a number of countries when births before age 19 are considered.

Further analyses suggest that in a number of countries, respondents aged 15-19 tend to concentrate reported ages at first birth in older adolescence. When we look at the reporting of births by individual year of age in Uganda, the 15-19 age-group in the first survey reports lower percentages of births occurring at age 16 or earlier than does the 20-24 age-group in the second survey, as well as higher percentages of births at age 18 (Figure 1). In Senegal, only levels of first births occurring before age 15 are lower among women aged 16-19 in the first survey than among women aged 20-24 in the second survey. For first births later in adolescence (e.g., at ages 17 and 18), the 15-19 agegroup in the first survey provides estimates higher than those for the 20-24 age-group in the second survey. Similar patterns are seen in Mali, Madagascar and Bolivia, but not in Ghana or Benin, where the proportion of births at age 18 reported by the 15-19 age-group in the first survey was equal to or lower than the proportion reported by the 20-24 age-group in the second survey (not shown).

When we examine the data for age at first marriage or union, the differences between 15-19-year-olds in the first survey and 20-24-year-olds in the second survey are smaller, but follow the same pattern as those for first births (Table 2, page 213). The percentage differences are highest for marriages occurring before age 15 and lowest for those occurring before age 19 in terms of percentage change, although again the percentage-point difference increases for most of these countries. The one exception is Senegal, where the differences in reports of marriage before ages 15 and 16 are very small, and a lower proportion of marriage before age 19 was reported in the second survey than in the first. In all three Latin American countries, the differences for reported marriage are greater than those for first birth. Again, confidence intervals are modest, but could explain the differences for marriage before age 15 and before age 16 in Ghana, Senegal and Bolivia. There is also evidence that respondents in some countries, such as Uganda and Madagascar, concentrate reported age at marriage or 
first union in older adolescence (not shown)

Differences in the incidence and timing of sexual debut by age-group and survey are much smaller and less consistent than those for first birth and marriage (Table 3, page 214). In Uganda, Senegal, the Dominican Republic and Bolivia, the proportions of women reporting sexual debut before ages 15 and 16 are higher in the second survey's 2024 age-group than in the first survey's 15-19 age-group. However, with the exception of the Dominican Republic, the differences are less than for first births and, in Uganda and Bolivia, are also less than for marriage. In Colombia, Mali and Madagascar, the percentage differences across cohorts in the proportions reporting sexual debut before ages 15,16 and 19 are less than $15 \%$, and in some cases, are nonexistent or negative. However, in Benin, women in the first survey's 15-19 age-group report higher rates of sexual debut before age 15 or 16 than women in the second survey's 20-24 age-group. However, when we examine the confidence intervals, most apparent differences could be explained by sampling error.

If some of the larger differences in the younger agegroups cannot be attributed to sampling error, the question of which estimates are more accurate is raised. To address this question, we examined whether estimates for the 16-19 age-groups were consistent with temporal trends based on estimates from earlier birth cohorts. Figure 2 (page 215) shows trend graphs for estimates of the percentage of women who report first birth before the age of 16 by age-group for the first survey in each of the SubSaharan African countries examined. Uganda shows a particularly large and unprecedented increase in the estimate of early initiation of childbearing between the 16-19 and the 20-24 age-groups. Senegal and Mali also show this increase, but this could plausibly indicate an overestimation from the 20-24-year-old group in these countries, as estimates for the 20-24 age-groups are higher than might be expected given earlier trends. It is therefore difficult to gain any clear understanding from these graphs as to whether the 20-24 age-group or the 16-19 age-group provides more reliable data. Similar patterns were demonstrated for marriage (not shown).

To further examine the trends in age at first birth, we plotted estimates from multiple surveys for two SubSaharan African countries by aligning the birth cohorts (e.g., in Uganda, women born in 1981-1986 will have been included in one of the three surveys at ages 16-19, 20-24 or 25-29, respectively, and this graph allows direct comparison). In Mali, there is a remarkable level of consistency for estimates from the two most recent surveys, with the exception of the 16-19 age-group from the 2001 survey and the corresponding estimate from the 20-24 agegroup from the subsequent 2006 survey (Figure 3, page 215). The estimates for the 16-19 age-groups are markedly lower. The earliest survey presented (1995-1996) has lower estimates for all birth cohorts. The pattern for Uganda shows less overall consistency, but again demonstrates a much greater difference between the estimates for
TABLE 2. Proportions (and confidence intervals) of women marrying before ages 15 , 16 and 19, according to their reports at ages 15-19 in the first DHS and at ages 20-25 in the second DHS, and the percentage difference and percentage-point difference between surveys, nine countries, 2001-2011

\begin{tabular}{|c|c|c|c|c|}
\hline $\begin{array}{l}\text { Country and age } \\
\text { at first marriage }\end{array}$ & Age 15-19 & Age 20-24 & $\begin{array}{l}\text { Percentage } \\
\text { difference }\end{array}$ & $\begin{array}{l}\text { Percentage- } \\
\text { point } \\
\text { difference }\end{array}$ \\
\hline Benin & 2001 & 2006 & & \\
\hline$<15$ & $4.9(3.8-6.2)$ & $7.9(7.0-8.8)$ & 61.2 & 3.0 \\
\hline$<16$ & $9.8(7.9-11.7)$ & $15.7(14.5-17.0)$ & 60.2 & 5.9 \\
\hline$<19$ & $39.9(33.2-46.6)$ & $46.4(44.6-48.1)$ & 16.3 & 6.5 \\
\hline Ghana & 2003 & 2008 & & \\
\hline$<15$ & $2.7(1.7-3.7)$ & $4.9(3.5-6.3)$ & 81.5 & 2.2 \\
\hline$<16$ & $5.7(4.2-7.3)$ & $9.4(7.5-11.3)$ & 64.9 & 3.7 \\
\hline$<19$ & $27.7(21.2-34.1)$ & $32.5(29.4-35.6)$ & 17.3 & 4.8 \\
\hline Madagascar & 2003 & 2008-2009 & & \\
\hline$<15$ & $8.8(7.4-10.2)$ & $14.4(13.1-15.7)$ & 63.6 & 5.6 \\
\hline$<16$ & $17.0(14.9-19.1)$ & $25.2(23.6-26.8)$ & 48.2 & 8.2 \\
\hline$<19$ & $47.2(41.4-53.0)$ & $60.0(58.1-61.8)$ & 27.1 & 12.8 \\
\hline Mali & 2001 & 2006 & & \\
\hline$<15$ & $19.4(17.9-20.9)$ & $24.6(23.0-26.3)$ & 26.8 & 5.2 \\
\hline$<16$ & $35.2(33.2-37.3)$ & $42.5(40.6-44.3)$ & 20.7 & 7.3 \\
\hline$<19$ & $70.3(65.6-75.0)$ & $79.6(78.1-81.2)$ & 13.2 & 9.3 \\
\hline Senegal & 2005 & 2010-2011 & & \\
\hline$<15$ & $10.1(9.2-11.2)$ & $12.0(10.9-13.1)$ & 18.8 & 1.9 \\
\hline$<16$ & $17.9(16.4-19.3)$ & $19.2(17.8-20.5)$ & 7.3 & 1.3 \\
\hline$<19$ & $44.9(40.7-49.1)$ & $41.2(39.5-42.9)$ & -8.2 & -3.7 \\
\hline Uganda & 2006 & 2011 & & \\
\hline$<15$ & $3.0(2.2-3.8)$ & $9.9(8.5-11.4)$ & 230.0 & 6.9 \\
\hline$<16$ & $8.6(7.2-10.0)$ & $18.6(16.7-20.5)$ & 116.3 & 10.0 \\
\hline$<19$ & $47.6(42.2-53.0)$ & $51.2(48.8-53.7)$ & 7.6 & 3.6 \\
\hline Bolivia & 2003 & 2008 & & \\
\hline$<15$ & $2.4(1.9-2.9)$ & $3.2(2.6-3.9)$ & 33.3 & 0.8 \\
\hline$<16$ & $5.4(4.6-6.2)$ & $7.6(6.7-8.6)$ & 40.7 & 2.2 \\
\hline$<19$ & $24.8(21.5-28.2)$ & $29.1(27.4-30.9)$ & 17.3 & 4.3 \\
\hline Colombia & 2005 & 2010 & & \\
\hline$<15$ & $4.5(4.0-5.0)$ & $5.6(5.1-6.1)$ & 24.4 & 1.1 \\
\hline$<16$ & $8.6(7.8-9.3)$ & $10.0(9.4-10.7)$ & 16.3 & 1.4 \\
\hline$<19$ & $31.7(29.1-34.2)$ & $29.9(28.9-30.9)$ & -5.7 & -1.8 \\
\hline Dominican Republic & 2005 & 2010 & & \\
\hline$<15$ & $10.4(9.5-11.3)$ & $13.9(12.8-14.9)$ & 33.7 & 3.5 \\
\hline$<16$ & $19.1(17.8-20.4)$ & $23.3(22.1-24.5)$ & 22.0 & 4.2 \\
\hline$<19$ & $44.5(41.2-47.7)$ & $47.0(45.5-48.4)$ & 5.6 & 2.5 \\
\hline
\end{tabular}

16-19-year-olds and 20-24-year-olds than between any other data points (Figure 4, page 216). Again, estimates for the age 16-19 cohort are low. While by no means conclusive, this does provide evidence that underestimation in the 16-19 age-group is more plausible for Uganda and Mali; similar patterns were also found for Senegal (not shown).

In the DHS, one of the most common sources of error in fertility estimates is that births are backdated to more than five years earlier to avoid completing the questionnaire for children under age five. If this were a cause of overreporting early adolescent births in the 20-24 age-groups, these overreported births would need to be concentrated among women aged 20 and 21 years to push first births below the age 15 and age 16 cut-offs. To assess the possibility, we analyzed the percentage of women reporting a first birth be- 


\begin{tabular}{|c|c|c|c|c|}
\hline $\begin{array}{l}\text { Country and age } \\
\text { at first sex }\end{array}$ & Ages 15-19 & Ages 20-24 & $\begin{array}{l}\text { Percentage } \\
\text { difference }\end{array}$ & $\begin{array}{l}\text { Percentage- } \\
\text { point difference }\end{array}$ \\
\hline Benin & 2001 & 2006 & & \\
\hline$<15$ & $16.0(13.9-18.0)$ & $11.5(10.4-12.6)$ & -28.1 & -4.5 \\
\hline$<16$ & $31.9(30.7-33.0)$ & $25.4(23.9-26.9)$ & -20.4 & -6.5 \\
\hline$<19$ & $79.5(74.0-85.0)$ & $70.8(69.2-72.4)$ & -10.9 & -8.7 \\
\hline Ghana & 2003 & 2008 & & \\
\hline$<15$ & $7.3(5.8-8.8)$ & $7.2(5.4-8.9)$ & -1.4 & -0.1 \\
\hline$<16$ & $18.9(16.3-21.4)$ & $16.4(14.0-18.9)$ & -13.2 & -2.5 \\
\hline$<19$ & $64.4(57.4-71.3)$ & $59.9(56.7-63.2)$ & -7.0 & -4.5 \\
\hline Madagascar & 2003 & 2008-2009 & & \\
\hline$<15$ & $16.0(14.2-17.9)$ & $18.1(16.7-19.6)$ & 13.1 & 2.1 \\
\hline$<16$ & $33.9(31.3-36.5)$ & $33.4(31.6-35.1)$ & -1.5 & -0.5 \\
\hline$<19$ & $69.4(64.0-74.7)$ & $75.8(74.2-77.4)$ & 9.2 & 6.4 \\
\hline Mali & 2001 & 2006 & & \\
\hline$<15$ & $26.0(24.3-27.7)$ & $26.1(24.2-27.7)$ & 0.4 & 0.1 \\
\hline$<16$ & $47.4(45.3-49.6)$ & $48.2(46.3-50.1)$ & 1.7 & 0.8 \\
\hline$<19$ & $83.6(79.8-87.5)$ & $80.7(79.2-82.2)$ & -3.5 & -2.9 \\
\hline Senegal & 2005 & 2010-2011 & & \\
\hline$<15$ & $9.1(8.1-10.0)$ & $11.9(10.8-13.0)$ & 30.8 & 2.8 \\
\hline$<16$ & $16.9(15.5-18.3)$ & $20.5(19.1-21.9)$ & 21.3 & 3.6 \\
\hline$<19$ & $43.5(39.3-47.6)$ & $45.2(43.4-46.9)$ & 3.9 & 1.7 \\
\hline Uganda & 2006 & 2011 & & \\
\hline$<15$ & $11.8(10.4-13.3)$ & $16.1(14.3-17.9)$ & 36.4 & 4.3 \\
\hline$<16$ & $24.5(22.3-26.7)$ & $29.0(26.8-31.2)$ & 18.4 & 4.5 \\
\hline$<19$ & 70.7 (65.8-75.6) & $71.0(68.8-73.2)$ & 0.4 & 0.3 \\
\hline Bolivia & 2003 & 2008 & & \\
\hline$<15$ & $6.2(5.4-6.9)$ & $6.6(5.7-7.6)$ & 6.5 & 0.4 \\
\hline$<16$ & $14.6(13.4-15.9)$ & $16.2(14.8-17.5)$ & 11.0 & 1.6 \\
\hline$<19$ & $49.7(45.8-53.6)$ & $53.0(51.2-55.0)$ & 6.6 & 3.3 \\
\hline Colombia & 2005 & 2010 & & \\
\hline$<15$ & $13.7(12.9-14.5)$ & $13.8(13.0-14.6)$ & 0.7 & 0.1 \\
\hline$<16$ & $27.2(26.0-28.4)$ & $29.2(28.3-30.2)$ & 7.4 & 2.0 \\
\hline$<19$ & $66.4(63.8-68.9)$ & $74.4(73.4-75.4)$ & 12.0 & 8.0 \\
\hline Dominican Republic & 2002 & 2007 & & \\
\hline$<15$ & $12.8(11.8-13.8)$ & $16.3(15.2-17.3)$ & 27.3 & 3.5 \\
\hline$<16$ & $24.2(22.8-25.6)$ & $28.1(26.8-29.5)$ & 16.1 & 3.9 \\
\hline$<19$ & $55.0(51.9-58.2)$ & $63.0(61.6-64.4)$ & 14.5 & 8.0 \\
\hline
\end{tabular}

fore age 15,16 and 20 by the respondent's age in years on the day of the interview for the 20-24 age cohort for four countries (Senegal, Uganda, Benin and Mali). The sample sizes are small, but there appears to be a higher proportion of women aged 20 reporting births before age 16 in Senegal, Uganda and Benin, and before age 15 in Uganda, Mali and Benin. We suggest, however, that this is not sufficient to fully explain the very marked differences found between cohorts: For instance, in Benin, where women aged 20 report a higher proportion of births before ages 15 and 16 , we find that the estimate for women having a first birth before age 16 declines only slightly, from $8.2 \%$ to $7.1 \%$, if we compare the average for all women aged 20-24 with those aged 21-24 at the time of interview. In two countries, there is a particularly high proportion of women aged exactly 20 years reporting births before age 20 , which suggests that young mothers differentially misreport their age on a spe- cific year (i.e., age heaping, a recognized problem in surveys). As a further check, we examined births to women aged 15-22 by individual year for the 20-24 age cohort (using only women exposed to the full period) to investigate any heaping of births around the age of 20 years. Our findings did not show any evidence of misreporting, and a comparison of age at birth by individual years for the 20-24 and 25-29 age cohorts did not show any marked difference in patterns.

\section{DISCUSSION}

In the majority of the DHS data we analyzed, women aged 15-19 (and 16-19) report much lower percentages of marriages and first births occurring before ages 15 or 16 than do women aged 20-24 five years later. The observed differences in most countries cannot be explained by sampling error alone. There are several plausible explanations that account for the lack of consistency in reporting over time: Women aged 20-24 may be over- or misreporting marriage and first births before age 15 or 16 ; women aged 15-19 may be under- or misreporting births before ages 15 or 16; or some combination of the two. A number of previous studies analyzing DHS and similar survey data have indicated an increasing decline in first births and marriage for women aged 15-19 when examining trends using different birth cohorts from the same survey, which likely indicates inconsistencies in reporting. ${ }^{22-25}$ Our results show that inconsistencies between surveys in estimates of these widely published indicators of adolescent health and wellbeing are most pronounced when very young ages are used as the cut-off, particularly age 15 and age 16

Our analyses suggest that neither the backdating of births nor the omission of early births or marriages is likely to be the sole or main cause of misreporting. Underestimation of early adolescent events among the 15-19 agegroup may also arise if respondents, when asked to list the members of their household, selectively omit adolescents or lower the age of those who are already married or have given birth before age 15 , because these adolescents would be removed from the sample from which estimates are determined. Previous studies have reported clear evidence of ages being incorrectly assigned to the 15-19 age-group from the 10-14 age-group in the household roster component of the survey as a result of misreporting or misrecording. ${ }^{7,25}$ However, it has not been shown whether young married women or mothers are overrepresented among those whose ages are misreported in the household roster. Again, in countries in which the overall percentages of marriage and first births are similar for women younger than 20, this is unlikely to be the sole cause of discrepancy because this would lead to a discrepancy in reporting for all adolescent births and marriages.

Overstatement of age by adolescents is a plausible explanation for underestimation of early adolescent births and marriages among respondents aged 15-19-an explanation advanced by authors of previous studies identifying inconsistencies in reporting of first births and marriages 
for women aged 15-19 across surveys. ${ }^{23-26}$ If age overstatement is most prevalent among younger adolescent respondents, this could explain why we find particularly marked differences in estimates between surveys. In Sub-Saharan Africa, age overstatement may be compounded by a lack of completeness in the record of dates for marriages and first births and the postinterview application of imputation. ${ }^{27}$

An unexpected finding was the much greater consistency of sexual debut data than of marriage and first birth data (although this study cannot confirm that sexual debut data are more accurate). One possible reason for this consistency is that if women are unmarried and have not had a birth, there is no need to place sexual debut within a sequence of events. Inconsistency could stem from the need for respondents to present these events within a socially acceptable sequence. Another possibility is that adolescents may be more likely than others to overstate their ages if they are married or have had a child.

The differences in apparent reporting accuracy are somewhat difficult to explain conclusively, but are likely to reflect the underlying social and cultural differences among the countries included. There are marked variations across the countries in this study for a range of factors, such as legal age of marriage, female education and birth registration, all of which could influence accuracy of reporting as well as affect the extent to which young women feel obliged to overstate their age. It is also important to note that another study has identified age understatement in young women in Bangladesh (possibly related to dowry payments), ${ }^{28}$ which again highlights how cultural issues may influence data. An initial analysis did not find any clear pattern of association between these three factors and the degree of discrepancies in reporting between the cohorts, so it is likely that the differences between countries are the result of a combination of factors, including the degree to which early sexual activity, marriage and childbearing are proscribed by prevailing societal norms.

We offer a number of recommendations to analysts using these data. Many of the adverse effects of adolescent marriage and motherhood are likely to be concentrated among those who are younger, so it is important to disaggregate data by age to show trends and patterns for younger adolescents. Where it is feasible to check trends, doing so would help identify inconsistencies. In some of the countries we investigated, for example, Uganda, Senegal and Mali, we found that responses from the 20-24 age cohort appeared to be more consistent than those from other cohorts. However, this link may not exist in other countries and survey years. We advise against the widespread practice of reporting declines in very early adolescent pregnancy and marriage on the basis of comparisons of five-year age-group data collected in the same survey.

It is possible that these inconsistencies might be reduced by changes in data collection rather than changes in analysis. Age overstatement by the youngest DHS respondents may be the result of social desirability bias. If this is the case, a number of measures can be considered
FIGURE 2. Proportion of women reporting first birth before age 16, by age-group in the first DHS, six Sub-Saharan African countries

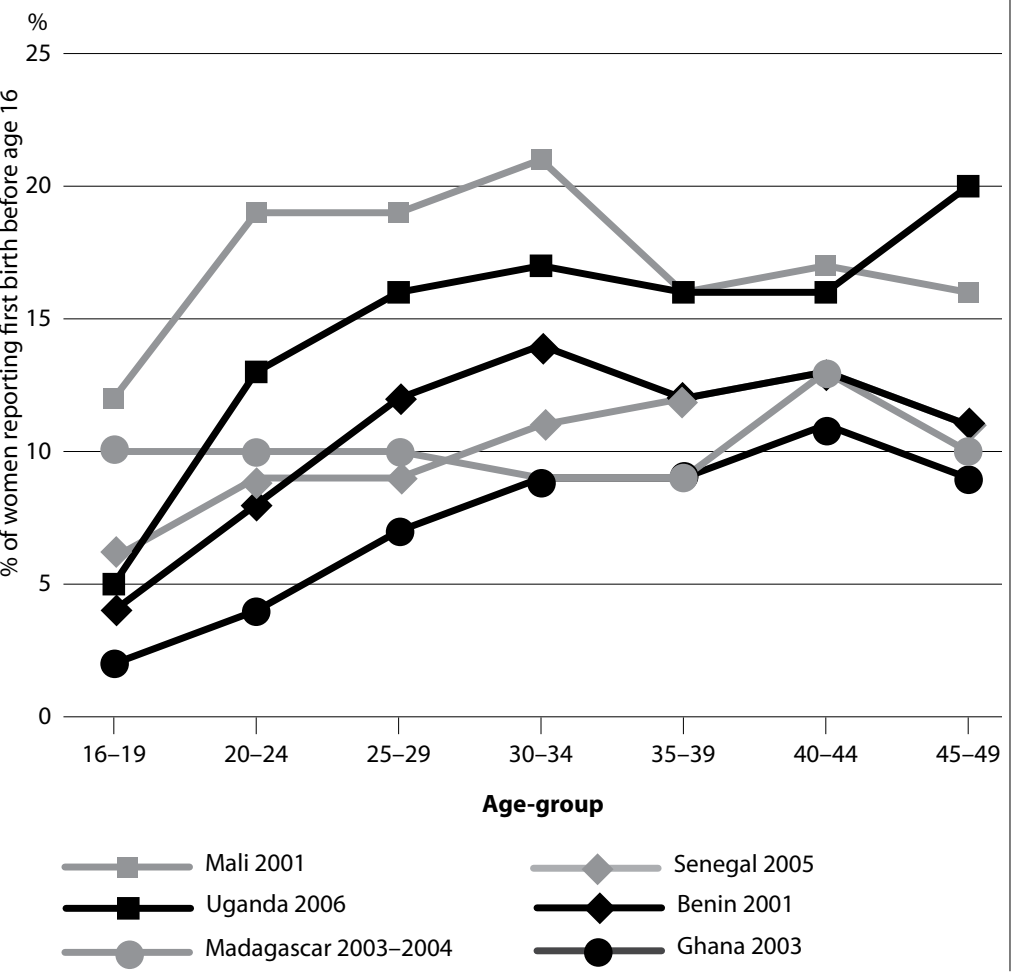

as means of improving the reporting of adolescent sexual health data for the DHS, which is currently carried out as a face-to-face interview. Beguy et al. emphasize the importance of ensuring privacy during the interview. ${ }^{15}$ Interviewers could benefit from additional training and support to create spaces in settings that are crowded or that lack privacy. Some studies have found that reducing the potential

FIGURE 3. Proportion of women reporting first birth before age 16, by birth cohort, Mali, 1995-1996, 2001 and 2006 DHS

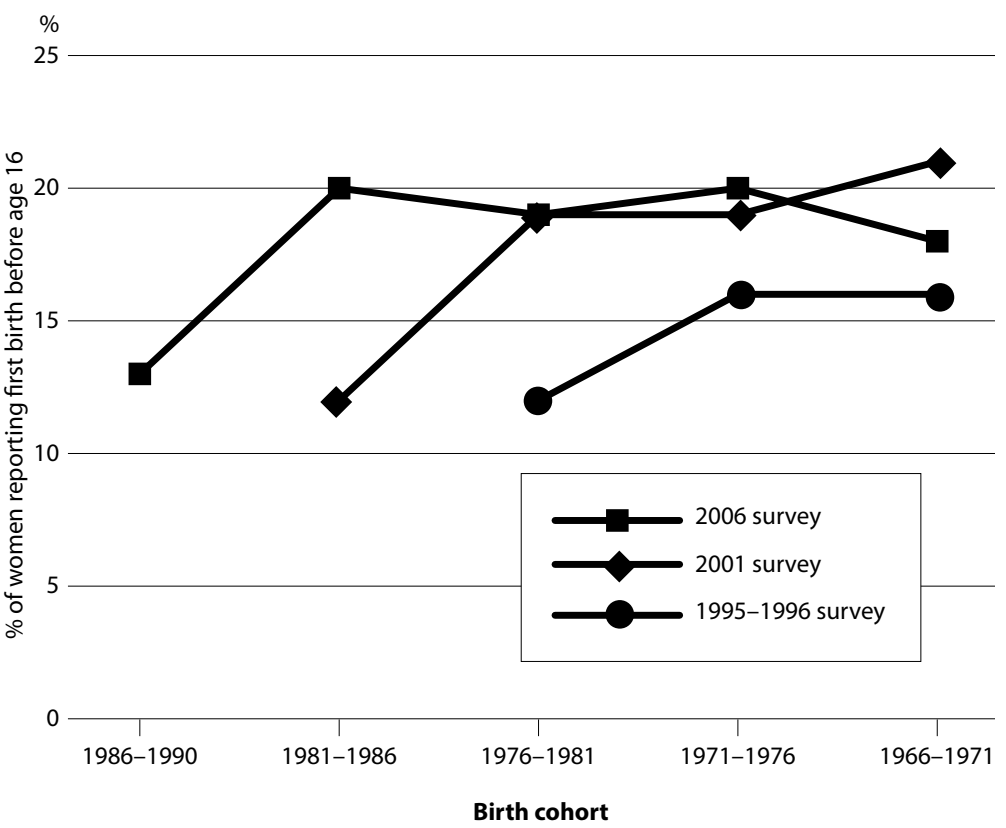




\section{FIGURE 4. Proportion of women reporting first birth before age 16 , by birth cohort, Uganda, 2000-2001, 2006 and 2011 DHS}

$\%$

$$
25
$$

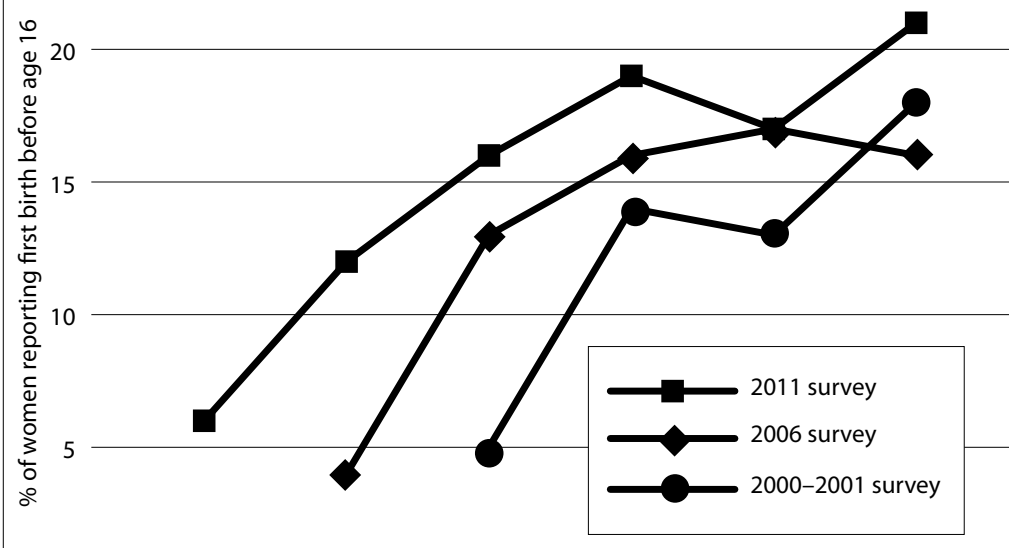

0

1991-1995 1986-1991 1981-1986 1976-1981 1971-1976 1966-1971

\section{Birth cohort}

influence of interviewers on respondent reports through, for example, use of self-completed questionnaires may improve data quality. ${ }^{2}$ Hewett et al. found that adolescents are more likely to report sensitive sexual behavior with audio computer-assisted self-interviewing (ACASI) than in face-to-face interviews in some contexts. ${ }^{29}$ However, in other contexts, benefits from ACASI are not obvious or computer-based approaches have not been well accepted by participants. ${ }^{3,30}$ Last, interviewers could be guided to perform more consistency checks during the interview, checking, for example, a respondent's self-reported age with the age recorded in the household roster.

There is a need for more country-specific research to validate the accuracy of reporting of early reproductive events from large surveys. A number of studies have compared self-reported data collected using different methods, 2,29,30 but a more accurate method would be to compare survey data with some form of vital registration, prospective records of events or links with clinic records. Such a method might be suitable in a number of contexts in which data are gathered continuously, either by reliable vital registration or demographic sentinel surveillance systems.

\section{Conclusion}

This study finds significant inconsistencies between surveys in the reporting of early adolescent first births and marriage, with reports from women aged 15-19 being significantly lower than reports from women aged 20-24 in surveys five years later. The trend is particularly marked in a number of Sub-Saharan African countries. These inconsistencies have potentially important implications for the accuracy of early adolescent sexual event data, as well as for median estimates of age at marriage and first birth.
We strongly recommend that caution should be exercised when inferring changes in early adolescent sexual and reproductive health on the basis of estimates from the DHS. Attention should focus on the development of data collection instruments to reduce misreporting, as well as correction methods for estimates from self-reported data of women sampled in repeated household surveys.

\section{REFERENCES}

1. Temin M and Levine R, Start with a Girl: A New Agenda for Global Health, Washington, DC: Center for Global Development, 2009.

2. Plummer ML et al., "A bit more truthful": the validity of adolescent sexual behaviour data collected in rural northern Tanzania using five methods, Sexually Transmitted Infections, 2004, 80(Suppl. 2):ii49-ii56.

3. Mensch BS, Hewett PC and Erulkar AS, The reporting of sensitive behavior by adolescents: a methodological experiment in Kenya, Demography, 2003, 40(2):247-268

4. Mensch BS et al., Challenges in measuring the sequencing of life events among adolescents in Malawi: a cautionary note, Demography, 2014, 51(1):277-285.

5. Bankole A et al., Sexual behavior, knowledge and information sources of very young adolescents in four sub-Saharan African countries, African Journal of Reproductive Health, 2007, 11(3):28-43.

6. Igras SM et al., Investing in very young adolescents' sexual and reproductive health, Global Public Health, 2014, 9(5):555-569.

7. Pullum TW, An assessment of age and date reporting in the DHS surveys, 1985-2003, DHS Methodological Reports, Calverton, MD, USA: Macro International, 2006, No. 5

8. Locoh T, Social change and marriage arrangements: new types of union in Lome, Togo, in: Bledsoe C and Pison G, eds., Nuptiality in Sub-Saharan Africa, Oxford, UK: Clarendon Press, 1994, pp. 215-230.

9. Speizer IS, A marriage trichotomy and its applications, Demography, 1995, 32(4):533-542.

10. Meekers D, The process of marriage in African societies: a multiple indicator approach, Population and Development Review, 1992, 18(1):61-78.

11. Hosegood V, Women, marriage and domestic arrangements in rural KwaZulu-Natal, South Africa, in: Claassens A and Smythe D, eds., Marriage, Land and Custom: Essays on Law and Social Change in South Africa, Claremont, South Africa: Juta and Company, 2003, pp. 143-168.

12. Garenne M, Age at marriage and modernisation in Sub-Saharan Africa, Southern African Journal of Demography, 2004 9(2): 59-79.

13. Hosegood V, McGrath N and Moultrie T, Dispensing with marriage: marital and partnership trends in rural KwaZulu-Natal, South Africa 2000-2006, Demographic Research, 2009, 20(13):279312

14. Arnold F and Blanc A, Fertility levels and trends, DHS Comparative Studies, Calverton, MD, USA: Institute for Resource Development/ Macro International, 1990, No. 2.

15. Beguy D et al., Inconsistencies in self-reporting of sexual activity among young people in Nairobi, Kenya, Journal of Adolescent Health, 2009, 45(6):595-601

16. United Nations Children's Fund (UNICEF), Early Marriage: Child Spouses, Florence, Italy: UNICEF Innocenti Research Centre, 2001

17. Borkotoky K and Unisa S, Indicators to examine quality of large scale survey data: an example through district level household and facility survey, PLoS ONE, 2014, 9(3):e90113.

18. Aziz KMA and Maloney C, Life stages, gender and fertility in Bangladesh, Monograph No. 3, Dhaka, Bangladesh: International Centre for Diarrhoeal Disease Research, 1985, http://dspace.icddrb. org/dspace/bitstream/123456789/2564/1/Life+stages+gender+and+f ertility+in+bangladesh,+Monograph+No+3.pdf

19. Curtis S, An assessment of the quality of data used for direct estimation of infant and child mortality in DHS II surveys, 
Demographic and Health Surveys Occasional Paper, Calverton, MD, USA: Macro International, 1995, No. 3.

20. Neal S and McGowan T, eds., The measurement of neonatal mortality: How reliable is Demographic and Household Survey data? ESRC Centre for Population Change Working Paper Series, Southampton, UK: University of Southampton, 2012, No. 25.

21. Zaba B et al., Estimation of levels and trends in age at first sex from surveys using survival analysis, Measure Evaluation Project Working Paper, 2002, No. 51, https://www.iywg.org/sites/iywg/files/ wp-02-51.pdf.

22. Gage AJ, An Assessment of the Quality of Data on Age at First Union, First Birth, and First Sexual Intercourse for Phase II of the Demographic and Health Surveys Program, Calverton, MD, USA: Macro International, 1995.

23. Hussein S, An exploration of nuptuality patterns in Egypt and the Maghreb countries, unpublished dissertation, London: University of London, 2002, https://www.academia.edu/2298557/.

24. Coale A, A reassessment of fertility trends in Egypt, taking account of the Egyptian fertility survey, in: Awad M and Samir F, eds., Demographic Responses to Modernization, Cairo: Central Agency for Mobilization and Public Statistics, 1988, pp. 21-43.

25. Blanc AK and Rutenberg N, Assessment of the quality of data on age at first sexual intercourse, age at first marriage and age at first birth in the Demographic and Health Surveys, in: Institute for Resource Development, An assessment of DHS-I data quality, DHS Methodological Reports, Columbia, MD, USA: Institute of Resource Development/Macro System, 1990, pp. 39-79.

26. Makinson C, Age Overstatement Among Young Women and its Effect on Estimates of Fertility and Proportions Married at Young Ages, Princeton, NJ, USA: Office of Population Research, Princeton University, 1984, cited in Singh S, Evaluation of data quality in: Cleland J and Scott C, eds., The World Fertility Survey: An Assessment, New York: Oxford University Press, 1987, pp. 618-643.

27. Machiyama K, A re-examination of recent fertility declines in SubSaharan Africa, DHS Working Papers, Calverton MD, USA: ICF Macro, 2010, No. 68

28. Streatfield PK et al., Early marriage in Bangladesh: not as early as it appears, Asian Population Studies, 2015, 11(1):94-110.

29. Hewett PC, Mensch BS and Erulkar AS, Consistency in the reporting of sexual behaviour by adolescent girls in Kenya: a comparison of interviewing methods, Sexually Transmitted Infections, 2004, 80(Suppl. 2):ii43-ii48

30. Mensch BS et al., Sexual behavior and STI/HIV status among adolescents in rural Malawi: an evaluation of the effect of interview mode on reporting, Studies in Family Planning, 2008, 39(4):321-334.

\section{RESUMEN}

Contexto: La edad al momento del debut sexual, del primer matrimonio o primera unión y del primer parto destacan entre los indicadores más utilizados de salud y bienestar de las mujeres adolescentes. Sin embargo, la exactitud de las estimaciones para estos indicadores, particularmente en el caso de las adolescentes jóvenes, es poco comprendida.

Métodos: Para cada uno de nueve países en África y América Latina, se usaron datos de dos Encuestas Demográficas y de Salud (EDS) conducidas con un espacio de cinco años entre ellas, con el fin de examinar las respuestas de mujeres sobre su edad al momento del debut sexual, matrimonio o primera unión y primer parto. Se describe la consistencia de las estimaciones entre los datos de las encuestas y las cohortes de nacimiento, poniendo particular énfasis en el reporte de eventos ocurridos antes de los 15 y 16 años.

Resultados: Se encontraron marcadas diferencias en las es- timaciones para los primeros partos y matrimonios muy tempranos. Las mujeres en edades de 15 a 19 años tuvieron mucha menos probabilidad de reportar matrimonios y primeros partos antes de los 15 años de edad que las mujeres de la misma cohorte de nacimiento cuando se les preguntó cinco años después, a los 20 a 24 años de edad. El debut sexual temprano se reportó de manera más consistente que los matrimonios o partos tempranos en las encuestas consecutivas.

Conclusiones: Debe procederse con precaución al inferir cambios en la salud sexual y reproductiva durante la adolescencia temprana en base a estimaciones de las EDS. Deben realizarse mayores esfuerzos para desarrollar instrumentos de recolección de datos que reduzcan los errores en los datos autoreportados por mujeres muestreadas en las encuestas de hogares.

\section{RÉSUMÉ}

Contexte: L'âge au moment du premier rapport sexuel, du premier mariage ou de la première union et du premier accouchement est l'indicateur le plus largement utilisé concernant la santé et le bien-être des adolescentes. On ne cerne cependant pas bien la précision des estimations de cet indicateur multiple, pour les jeunes adolescentes surtout.

Méthodes: Pour chacun de neuf pays d'Afrique et d'Amérique latine, les données d'Enquête démographique et de santé (EDS) de deux enquêtes menées à cinq années d'intervalle servent à examiner les déclarations des femmes concernant leur âge au moment de leur premier rapport sexuel, premier mariage ou première union, et premier accouchement. La constance des estimations entre les enquêtes pour les cohortes de naissance est décrite, avec une attention particulière aux déclarations d'événements survenus avant l'âge de 15 et 16 ans.

Résultats: De nettes différences apparaissent dans les estimations pour les premiers accouchements et mariages très précoces. Les femmes de 15 à 19 ans sont beaucoup moins susceptibles de déclarer un mariage ou un premier accouchement avant l'âge de 15 ans que ne le sont les femmes de la même cohorte de naissance interrogées cinq ans plus tard, à l'âge de 20 à 24 ans. L'activité sexuelle précoce est déclarée avec plus de constance dans les enquêtes consécutives que les mariages ou accouchements précoces.

Conclusions: La prudence s'impose quant aux changements suggérés concernant la santé sexuelle et reproductive des jeunes adolescentes par les estimations issues des EDS. Il faudrait s'efforcer davantage de produire des instruments de collecte de données qui réduisent le rapport erroné de données auto-déclarées des femmes échantillonnées dans les enquêtes de ménage.

\section{Acknowledgments}

Sarah Neal's work on this article was funded through a British Academy Postdoctoral Fellowship. Victoria Hosegood's work on the article was supported with funding from the Economic and Social Research Council for project ES/J021202/1 "Improved Measures of the Family Environment in Longitudinal Population Studies of Child Health in Sub-Saharan Africa."

Author contact:S.Neal@soton.ac.uk 